\title{
Development of a PDRA Method for Detection of the D614G Mutation in COVID-19 Virus - Worldwide, 2021
}

\author{
Ziwei Chen ${ }^{1,2}$; Xinxin Shen²; Ji Wang²; Xiang Zhao²; Yuan Gao²; Ruiqin Zhang'; \\ Jinrong Wang'; Leping $\mathrm{Liu}^{3}$; Xinmin $\mathrm{Nie}^{1,, *}$; Xuejun $\mathrm{Ma}^{2,4,4}$
}

\section{ABSTRACT}

Background: COVID-19 infection is a major public health problem worldwide, and the D614G mutation enhances the infectivity of COVID-19.

Methods: A probe-directed recombinase amplification (PDRA) assay was discussed to detect the D614G mutation at $39{ }^{\circ} \mathrm{C}$ for $30 \mathrm{~min}$. The sensitivity, specificity, and reproducibility of the PDRA were evaluated by D614 and G614 recombinant plasmids. The clinical performance of PDRA assay was validated by testing of 53 previously confirmed COVID-19 positive RNAs and 10 negative samples. Direct sequencing was carried out in parallel for comparison.

Result: With good reproducibility and specificity, the PDRA assay worked well with the concentration in the range of $10^{3}-10^{7}$ copies/reaction. Compared with direct sequencing as a reference, the recombinase-aided amplification (RAA) assay obtained $100 \%$ sensitivity and $100 \%$ specificity using clinical samples.

Conclusions: A rapid, convenient, sensitive, and specific method to detect D614G mutation was developed, which offers a useful tool to monitor mutations in COVID-19 virus RNA.

\section{INTRODUCTION}

At the end of 2019, coronavirus disease 2019 (COVID-19) caused by COVID-19 virus, also known as SARS-CoV-2, was first discovered and quickly began to spread around the world (1). Some researchers evaluated and compared the whole genome sequences of circulating COVID-19 and found mutations associated with the infectivity of the virus. High-frequency mutations in the COVID-19 genome were found in nsp6, RNA polymerase, helicase, membrane glycoprotein, RNA primer, nucleocapsid phosphoprotein, and spike protein genes (2). One of the most critical mutations was the D614G of the spike protein gene (S), which is a replacement of aspartic acid (D) with glycine (G). The transmission of S-G614 mutants was stronger than that of S-D614 mutants because a newly-formed serine protease called elastase-2 in the S-G614 mutant could lead to an increase in enzyme cleavage efficiency and infectivity $(3-4)$.

The D614G mutation brings new challenges to the prevention and control of the epidemic, and there are few reported molecular detection methods for D614G mutation (5). Therefore, developing a detection method to distinguish S-G614 mutants from S-D614 mutants is highly important. Many conventional methods are available for detecting single nucleotide polymorphism (SNP), such as real-time PCR (6), DNA sequencing ( $(7)$, restriction fragment length polymorphism (RFLP) (8). However, these methods are either time-consuming and laborious or require more sophisticated instruments and skillful personnel.

Isothermal DNA amplification technology offers a good alternative to mutation detection due to its simplicity and rapidity. Among them, loop-mediated isothermal amplification (LAMP) is the most common method for SNP detection, but the design of LAMP primers is complex, and its application is limited by the requirement of a high temperature $\left(65^{\circ} \mathrm{C}\right)$ (9). There are also some mutation detection studies on recombinase polymerase amplification (RPA) (10), its sensitivity and specificity are similar with PCR, but expensive (7.7 USD/test). Recombinase-aided amplification (RAA) is a new isothermal amplification assay for various pathogens (11) and uses specific enzymes and proteins to quickly detect nucleic acid in less than 30 minutes at $39{ }^{\circ} \mathrm{C}$, and it is cheaper (4.6 USD/test). Recently, a modified RAA assay, probe-directed recombinase amplification (PDRA), was developed in our laboratory for detection of SNPs (12-13). In this study, a PDRA method for simple and quick differentiation of D614G mutation in COVID19 was reported. 


\section{MATERIALS AND METHODS}

\section{Clinical Sample Collection}

A total of 53 previously confirmed COVID-19 virus positive RNAs and 10 negative RNAs (from other respiratory viral pathogen-positive swab samples) were all stored in the National Institute for Viral Disease Control and Prevention of China CDC in Beijing, China.

\section{Direct Sequencing of Clinical Samples}

The QIAGEN OneStep RT-PCR Kit for PCR and sequencing were used for comparison. The PCR forward primer sequence was 5AATCTATCAGGCCGGTAGCAC-3. The reverse sequence was 5-CACCAATGGGTATGTCACACT3. (14) The PCR assay was performed in a $25 \mu \mathrm{L}$ reaction system containing $5 \mu \mathrm{L}$ of $5 \times \mathrm{PCR}$ buffer, 2 $\mu \mathrm{L}$ of One Step RT-PCR Enzyme Mix (QIAGEN), 1 $\mu \mathrm{L}$ dNTP mix, $0.1 \mu \mathrm{L}$ of RNase inhibitor (RRI), $2 \mu \mathrm{L}$ of primer mix $(10 \mu \mathrm{mol} / \mathrm{L})$, and $2 \mu \mathrm{L}$ of template nucleic acid using a CFX96 Real-Time PCR System (Bio-Rad, USA) under the following conditions: a 30 min reverse transcription step at $50{ }^{\circ} \mathrm{C}$, a $15 \mathrm{~min}$ denaturation step at $95^{\circ} \mathrm{C}$, and followed by 35 cycles at $94{ }^{\circ} \mathrm{C}$ for $30 \mathrm{~s}, 55^{\circ} \mathrm{C}$ for $1 \mathrm{~min}$, and $72{ }^{\circ} \mathrm{C}$ for $1 \mathrm{~min}$, a $10 \mathrm{~min}$ final extension step at $72{ }^{\circ} \mathrm{C}$, and finally kept at $4{ }^{\circ} \mathrm{C}$. The PCR products were then sent to Sangon Biotech (Shanghai, China) for sequencing.

\section{Design of Primer \& Probes for the PDRA Assay}

The PDRA assay included two real-time RAA reactions ( $A$ and $G$ ) to detect the $A$ and $G$ nucleotides of the D614G mutation (A23403G polymorphism), respectively. Each individual PDRA reaction contained a primer and a probe. The forward primers of the two reactions were the same, and there was only one nucleotide difference in the polymorphic site between the two probes. the primers and probe design were based on the $S$ protein sequence of SARS-CoV-2 with accession number MT252819.1. A forward primer and two specific reverse probes for A and $G$ nucleotides of A23403G polymorphism were designed using Oligo7 software. The primer is usually $30-35 \mathrm{bp}$ in length and the probe is usually 46-52 nucleotides in length, of which at least $30 \mathrm{nt}$ is located at the 5' end, adjacent to the internal base-free site mimic (tetrahydrofuran $[\mathrm{THF}])$ site, flanked by dT-fluorophore and the corresponding $\mathrm{dT}$-quencher group, and at least 3 nucleotides at the 3' end. At the same time, the mutation site was designed to be just before the THF site of each probe (Figure 1). The forward primer sequence was 5-TTGAGATTCTTGACATTACACC ATGTTCTTT-3. The reverse probe D sequence was 5-TAGCAACAGGGACTTCTGTGCAGTT AACATCCTGATAAAGAACAGC-3. The reverse probe $\mathrm{G}$ sequence was 5-TAGCAACAGGGACTTCT GTGCAGTTAACACCCTGATAAAGAACAGC-3. All the primers and probes were synthesized and purified by Sangon Biotech (Shanghai, China) using high-performance liquid chromatography (HPLC).

\section{PDRA Assay}

PDRA assay was performed using RAA kits (Jiangsu Province Qitian Biology Co., Ltd., China), and the reaction system was partially modified. The A and $G$ reactions were divided into two tubes (A and $G$ ). A reaction was carried out in a $50 \mu \mathrm{L}$ lyophilized reaction

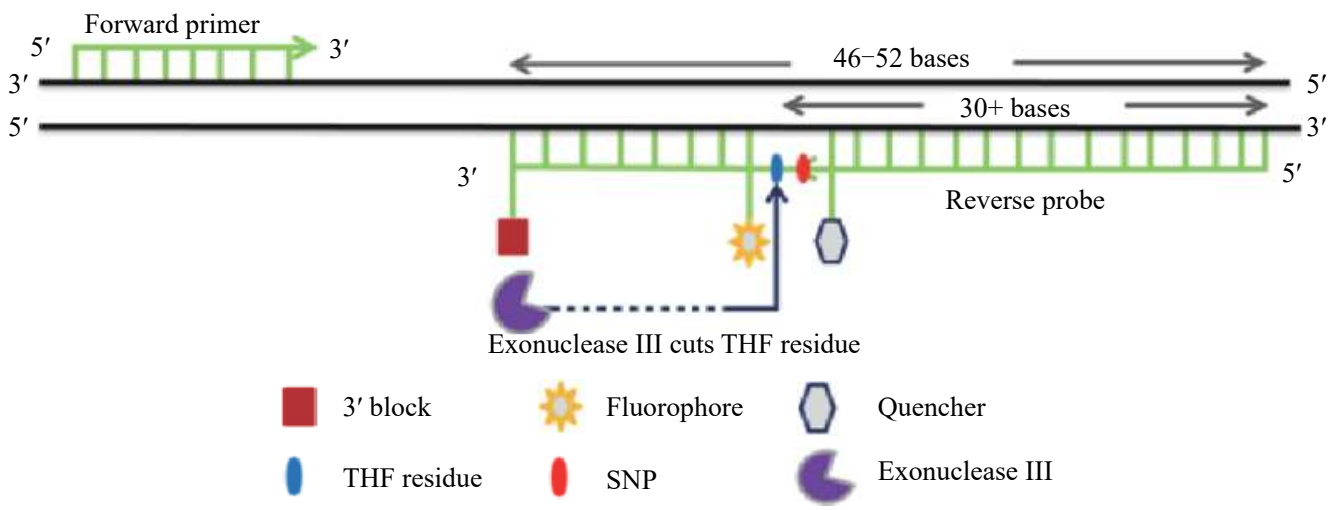

FIGURE 1. Design of the PDRA assay probe.

Abbreviations: $\mathrm{SNP}=$ single nucleotide polymorphism; THF=tetrahydrofuran. 
tube containing a dried enzyme precipitation $0.2 \mathrm{~mL}$, $25 \mu \mathrm{L}$ rehydration buffer, $18.2 \mu \mathrm{L} \mathrm{ddH}_{2} \mathrm{O}, 1.3 \mu \mathrm{L}$ forward primers $(10 \mu \mathrm{mol} / \mathrm{L}), 1 \mu \mathrm{L}$ A nucleotide specific PDRA probe $(10 \mu \mathrm{mol} / \mathrm{L}), 2 \mu \mathrm{L}$ DNA template, and $2.5 \mu \mathrm{L}$ magnesium acetate $(280$ $\mathrm{mmol} / \mathrm{L}$ ). G reaction was carried out in a $50 \mu \mathrm{L}$ lyophilized reaction tube containing a dried enzyme precipitation $0.2 \mathrm{~mL}, 25 \mu \mathrm{L}$ rehydration buffer, 17.9 $\mu \mathrm{L}$ ddH2O, $1.6 \mu \mathrm{L}$ forward primers $(10 \mu \mathrm{mol} / \mathrm{L}), 1 \mu \mathrm{L}$ G nucleotide specific PDRA probe $(10 \mu \mathrm{mol} / \mathrm{L}), 2 \mu \mathrm{L}$ DNA template, and $2.5 \mu \mathrm{L}$ magnesium acetate $(280$ $\mathrm{mmol} / \mathrm{L}$ ). The test tube was then transferred to the test tube rack of RAA fluorescence detection equipment QT-RAA-F7200 (Jiangsu Province Qitian Biology Co., Ltd., China) and incubated at $39{ }^{\circ} \mathrm{C}$ for $30 \mathrm{~min}$. Negative controls (water without nuclease) were included in each run.

\section{Interpretation of the PDRA Results}

When the slope of the fluorescence curve is $>20$, it is judged to be a positive result by the detector, and when the positive result of probe $\mathrm{D}$ appears earlier than that of probe $G$ and the time difference $\geq 3 \mathrm{~min}$, it is interpreted as S-D614 strain. When the positive result of probe $G$ appeared earlier than that of probe $D$ and the time difference $\geq 3 \mathrm{~min}$, it was interpreted as S-G614 mutant.

\section{Analytical Sensitivity, Specificity, and Reproducibility of PDRA Assay}

The recombinant plasmids of S-G614 mutant and S-D614 strain with a concentration in the 10 -fold range of $10^{2}$ copies $/ \mu \mathrm{L}$ to $10^{7}$ copies $/ \mu \mathrm{L}$ were used to validate the sensitivity and specificity of PDRA test. In different 5 days, 20 repeated experiments were carried out to verify its repeatability.

\section{Detection of Clinical Samples by PDRA Assay}

PDRA was used to detect 53 COVID-19 positive nucleic acid samples and 10 negative samples the results were compared with those of the sequencing results.

\section{RESULTS}

The sensitivity of PDRA for the detection of two recombinant plasmids was $10^{3}$ copies (Figure 2) and the reproducibility was shown in Table 1 . No cross reaction between two recombinant plasmids (G and D) was observed within at least 3-minute interval by corresponding probes in the detection range (Figure 3). A total of 63 clinical samples were typed by PDRA and direct sequencing. The sequencing results of 63 clinical samples were compared with the results of PDRA (Figure 4), and the coincidence rate was $100 \%$ (Table 2). Among the 63 clinical samples, there were 22 S-D614 mutants, 31 S-G614 mutants, and 10 negative samples.

\section{DISCUSSION}

At present, COVID-19 is still spreading rapidly all over the world. The virus spike protein is one of the best-targeted molecules for the development of vaccines or monoclonal antibodies against this virus $(15-16)$. Therefore, the mutation of $\mathrm{S}$ protein has special clinical significance. As one of the key mutations of $S$ protein, the D614G mutation has been concerned by many researchers. D614G mutation was first found in Germany (17). After that, Becerra-Flores et al. suggested that S-G614 mutants are more pathogenic and have higher mortality (18). These characteristics make S-G614 mutants rapidly become the dominant species and expand around the world (3).

Few studies reported D614G detection. The D614G detection method designed by Hashemi et al. (14), actually detected the mutation to V615V (19). Wholegenome sequencing is a powerful but costly tool to identify D614G mutants, which cannot be applied in primary laboratories for sequencing a large number of samples. Considering the importance of D614G compared with other mutations, a simple and rapid method to detect this mutation is favorable. Prior to this, PDRA has been successfully used to detect heart disease-related SNP and prostate cancer-related SNP (12-13).

The two PDRA reactions were carried out separately for two reasons: 1) in order to achieve good sensitivity for two different mutants; 2) in order to make the results of PDRA easier to interpret. Through the experiment, the detection limit of the PDRA was found to be in the range of $10^{3}-10^{7}$ copies/reaction. PDRA assay was not able to specifically distinguish the genotypes of the sample in the higher sample concentration $\left(>10^{7}\right.$ copies $)$ or led to false-negative results in the lower sample concentration $\left(<10^{3}\right.$ 

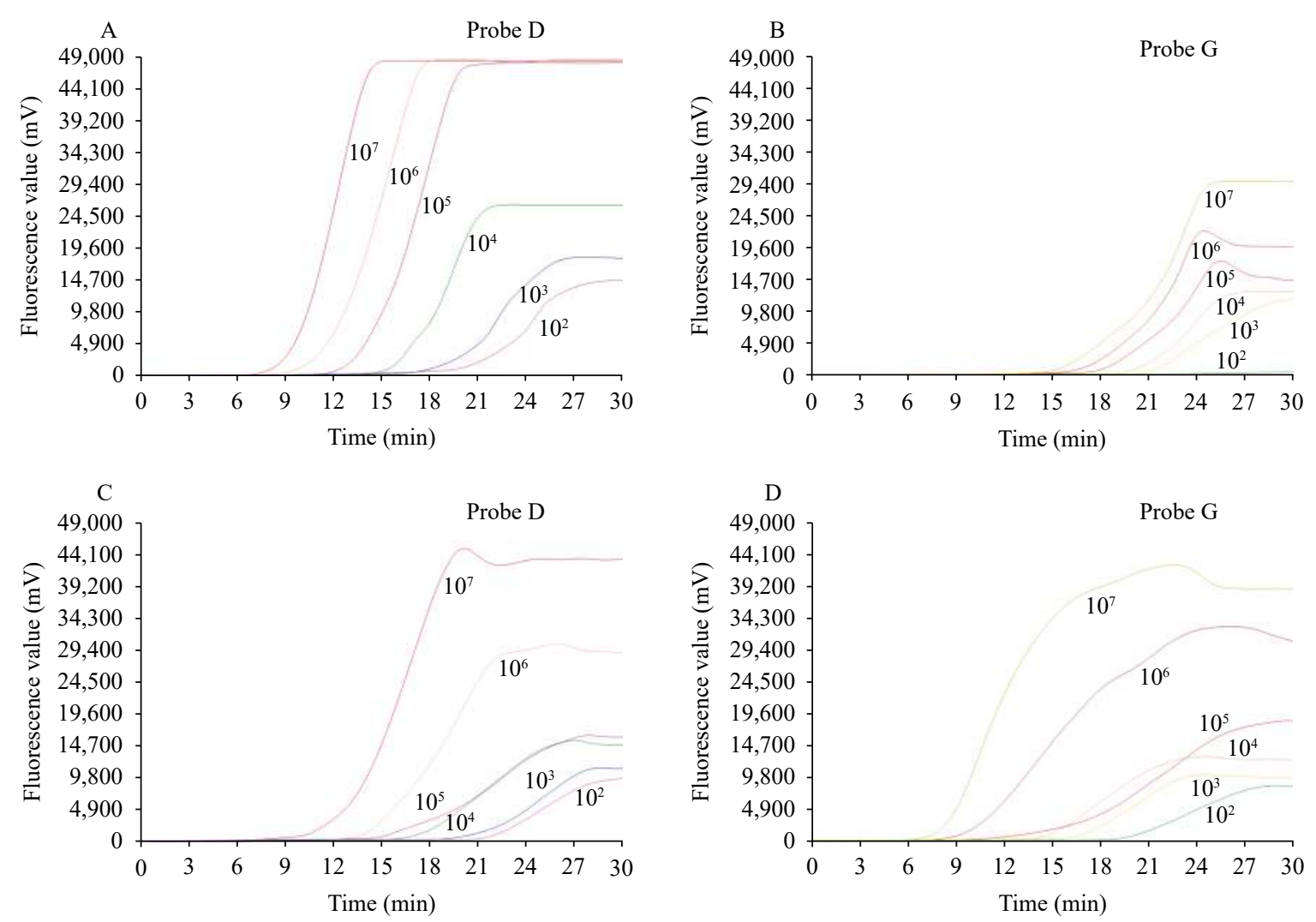

FIGURE 2. Sensitivity result of PDRA with recombinant plasmids. (A) Probe D tested S-D614 mutant recombinant plasmids; (B) Probe G tested S-D614 mutant recombinant plasmid; (C) Probe D tested S-G614 mutant recombinant plasmids; (D) Probe $\mathrm{G}$ tested S-G614 mutant recombinant plasmids.

Note: When the S-D614 strain recombinant plasmid was detected, the sensitivity of Probe D and Probe G was $10^{2}$ copies/reaction and $10^{3}$ copies/reaction, respectively, and the time to positivity by probe $\mathrm{D}$ at each concentration was less (at least $3 \mathrm{~min}$ interval) than that by probe G. When the S-G614 mutant recombinant plasmid was detected, the sensitivity of both Probe $D$ and Probe $G$ was $10^{2}$ copies/reaction. The time to positivity by probe $G$ at each concentration was less (at least 3 min interval) than that by probe $D$.

TABLE 1. The reproducibility of probe-directed recombinase amplification (PDRA) assay.

\begin{tabular}{cccc}
\hline Serial diluted DNA & No. of replicates tested & No. detected & Detection rate (\%) \\
\hline $10^{7}$ & 20 & 20 & 100 \\
$10^{6}$ & 20 & 20 & 100 \\
$10^{5}$ & 20 & 20 & 100 \\
$10^{4}$ & 20 & 20 & 100 \\
$10^{3}$ & 20 & 20 & 100 \\
$10^{2}$ & 20 & 2 & 10 \\
\hline
\end{tabular}

copies). Adding two reaction systems in one tube was attempted for saving time and cost but failed in the end. A possible reason is that there might be a competition mechanism between the two probes that makes them unable to react.

Although the PDRA method has some limitations, compared with direct sequencing, PCR and LAMP, PDRA possess the advantages of simple experimental conditions, short turnaround time and appropriate sensitivity and specificity. PDRA assay needs only 30 minutes to complete the detection and requires no sophisticated equipment. The detection process of PDRA is also simple and easy to learn. In view of the characteristics of PDRA and further improvement, PDRA will facilitate the detection of D614G mutations in resource-limited settings, particularly in locations where the contamination of the vaccine strain (D614) needs to be monitored and differentiated with 

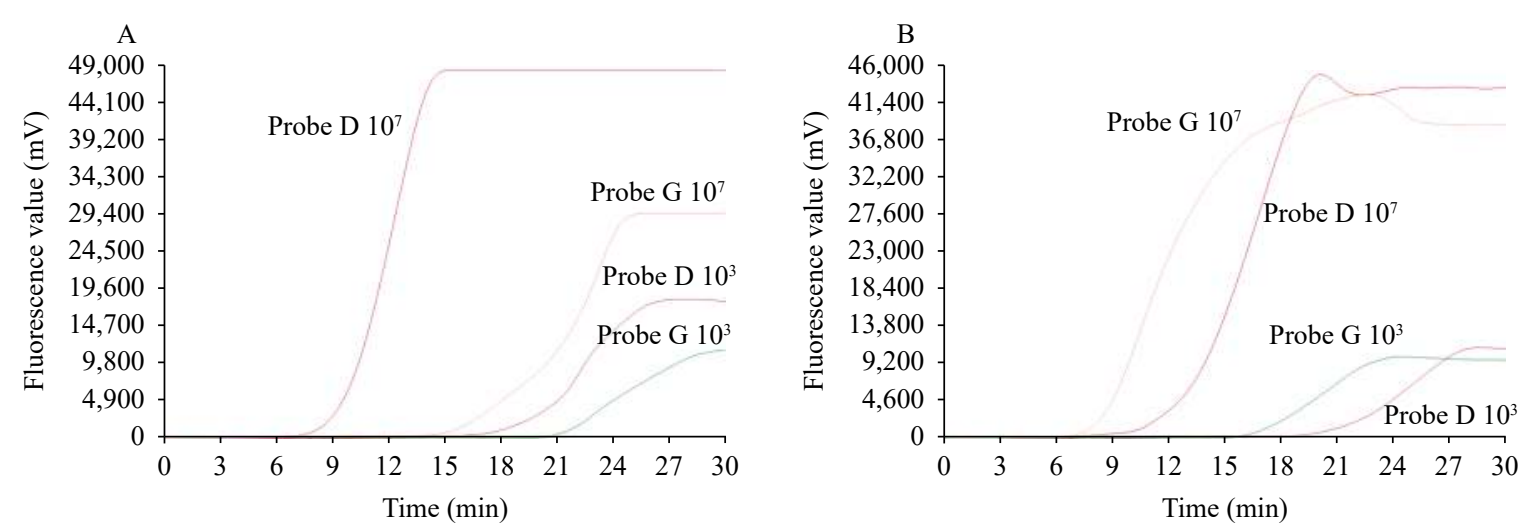

FIGURE 3. Specificity result of PDRA with recombinant plasmids. (A) S-D614 strain recombinant plasmid; (B) S-G614 mutant recombinant plasmid.

Note: When the $10^{7}$ copies of S-D614 strain recombinant plasmid were detected, the time to positivity by Probe D was less than that of Probe $\mathrm{G}$ by $6 \mathrm{~min}$. When the $10^{3}$ copies of recombinant plasmid were detected, the time to positivity by Probe $\mathrm{D}$ was less than that of Probe $\mathrm{G}$ by $4 \mathrm{~min}$. When the $10^{7}$ copies and $10^{3}$ copies of S-G614 mutant recombinant plasmids were detected, the time to positivity by Probe $G$ was less than that of Probe $D$ by 3 min.
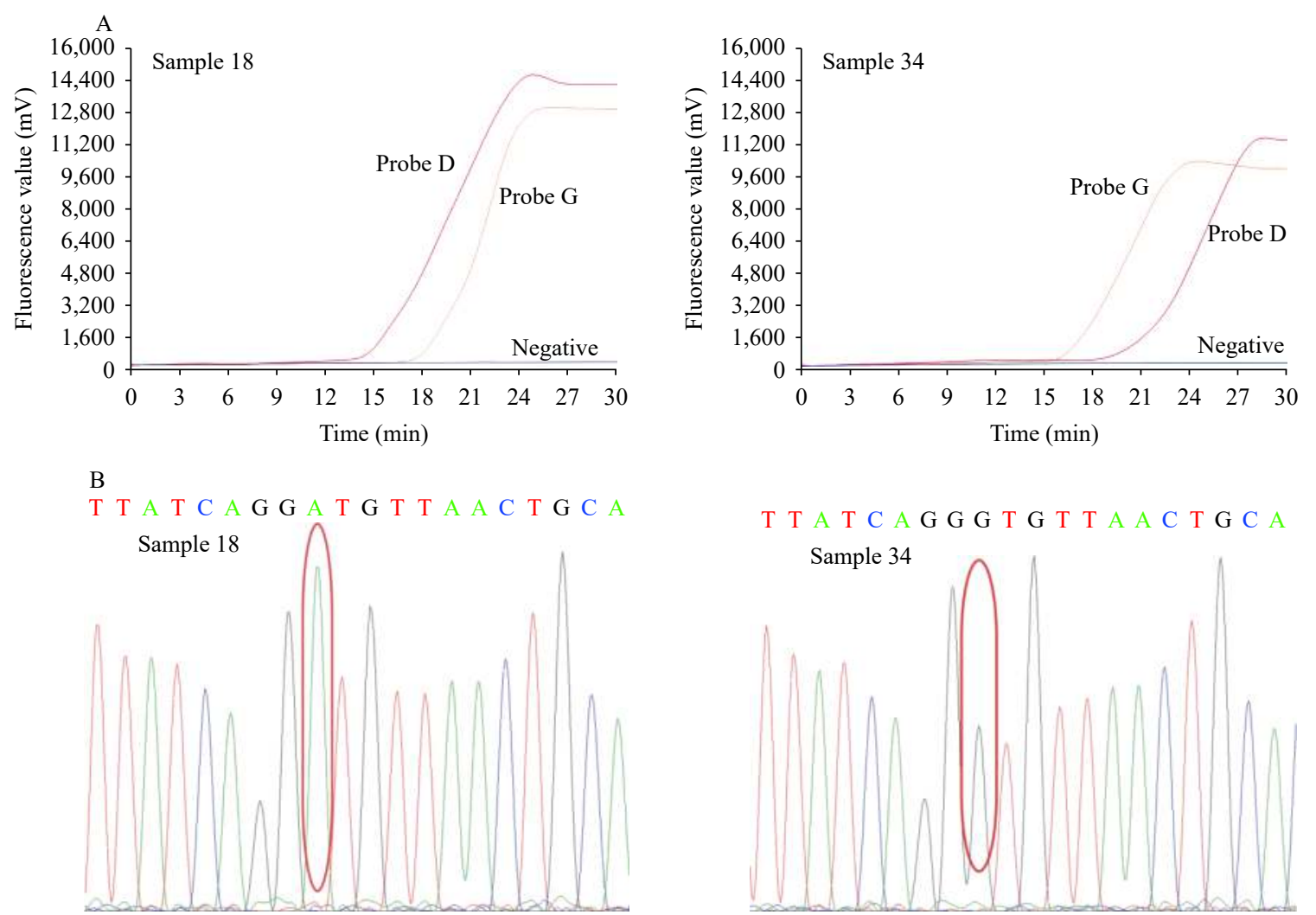

FIGURE 4. Comparison of the PDRA assay and direct sequencing results. (A) The PDRA results of sample 18 and sample 34; (B) The direct sequencing results of sample 18 and sample 34.

Note: Sample 18 was S-D614 mutant, and sample 34 was S-G614 mutant. Sample 18 was S-D614 mutant, and sample 34 was S-G614 mutant.

non-local circulating strains (G614) in China.

Conflicts of interest: No conflicts of interest were reported.

Availability of data and materials: The datasets used and/or analyzed during the current study available from the corresponding author on reasonable request.

Funding: Grants from the China Mega-Projects for Infectious Disease (2017ZX10302301-004-002), and Academician Hou Yunde Research Youth Fund Project (2019HYDQNJJ03). 
TABLE 2. Clinical sample typing results.

\begin{tabular}{cccc}
\hline Type & Sequencing & PDRA & Coincidence rate (\%) \\
\hline S-D614 & 22 & 22 & 100 \\
S-G614 & 31 & 31 & 100 \\
Negative & 10 & 10 & 100 \\
\hline
\end{tabular}

Abbreviation: PDRA=probe-directed recombinase amplification.

\section{doi: $10.46234 / \mathrm{ccdcw} 2021.115$}

\# Corresponding authors: Xinmin Nie, niexinmin7440@sina.com; Xuejun Ma, maxj@ivdc.chinacdc.cn.

\begin{abstract}
Department of Laboratory Medicine, Third Xiangya Hospital, Central South University, Changsha, Hunan, China; ${ }^{2}$ Department of NHC Key Laboratory of Medical Virology and Viral Diseases, National Institute for Viral Disease Control and Prevention, Chinese Center for Disease Control and Prevention, Beijing, China; ${ }^{3}$ Department of Blood Transfusion, Third Xiangya Hospital, Central South University, Changsha, Hunan, China; ${ }^{4}$ Center for Biosafety Mega-Science, Chinese Academy of Sciences, Wuhan, Hubei, China.
\end{abstract}

Submitted: April 01, 2021; Accepted: May 19, 2021

\section{REFERENCES}

1. Wiersinga WJ, Rhodes A, Cheng AC, Peacock SJ, Prescott HC. Pathophysiology, transmission, diagnosis, and treatment of coronavirus disease 2019 (COVID-19): a review. JAMA 2020;324(8):782 - 93. http://dx.doi.org/10.1001/jama.2020.12839.

2. Yin CC. Genotyping coronavirus SARS-CoV-2: methods and implications. Genomics 2020;112(5):3588 - 96. http://dx.doi.org/10. 1016/j.ygeno.2020.04.016

3. Bhattacharyya C, Das C, Ghosh A, Singh AK, Mukherjee S, Majumder $\mathrm{PP}$, et al. Global spread of SARS-CoV-2 subtype with spike protein mutation $\mathrm{D} 614 \mathrm{G}$ is shaped by human genomic variations that regulate expression of TMPRSS2 and MX1 genes. bioRxiv 2020. http://dx. doi.org/10.1101/2020.05.04.075911.

4. Groves DC, Rowland-Jones SL, Angyal A. The D614G mutations in the SARS-CoV-2 spike protein: implications for viral infectivity, disease severity and vaccine design. Biochem Biophys Res Commun 2021;538: 104 - 7. http://dx.doi.org/10.1016/j.bbrc.2020.10.109.

5. Bustin S, Coward A, Sadler G, Teare L, Nolan T. CoV2-ID, a MIQEcompliant sub-20-min 5-plex RT-PCR assay targeting SARS-CoV-2 for the diagnosis of COVID-19. Sci Rep 2020;10(1):22214. http://dx. doi.org/10.1038/s41598-020-79233-x.

6. Ulvik A, Ueland PM. Single nucleotide polymorphism (SNP) genotyping in unprocessed whole blood and serum by real-time PCR: application to SNPs affecting homocysteine and folate metabolism. Clin Chem 2001;47(11):2050 - 3. http://dx.doi.org/10.1093/clinchem/47. 11.2050 .
7. Ronaghi M. Pyrosequencing sheds light on DNA sequencing. Genome Res 2001;11(1):3 - 11. http://dx.doi.org/10.1101/gr.11.1.3.

8. Fukuen S, Fukuda T, Maune H, Ikenaga Y, Yamamoto I, Inaba T, et al. Novel detection assay by PCR-RFLP and frequency of the CYP3A5 SNPs, CYP $3 A 5^{*} 3$ and ${ }^{*} 6$, in a Japanese population. Pharmacogenetics 2002;12(4):331 - 4. http://dx.doi.org/10.1097/00008571-20020600000009 .

9. Yongkiettrakul S, Kampeera J, Chareanchim W, Rattanajak R, Pornthanakasem W, Kiatpathomchai W, et al. Simple detection of single nucleotide polymorphism in Plasmodium falciparum by SNPLAMP assay combined with lateral flow dipstick. Parasitol Int 2017;66(1):964 - 71. http://dx.doi.org/10.1016/j.parint.2016.10.024.

10. Zhao LW, Wang JC, Sun XX, Wang JF, Chen ZM, Xu XD, et al. Development and evaluation of the rapid and sensitive RPA assays for specific detection of Salmonella spp. in food samples. Front Cell Infect Microbiol 2021;11:631921. http://dx.doi.org/10.3389/fcimb.2021. 631921.

11. Shen XX, Qiu FZ, Shen LP, Yan TF, Zhao MC, Qi JJ, et al. A rapid and sensitive recombinase aided amplification assay to detect hepatitis $\mathrm{B}$ virus without DNA extraction. BMC Infect Dis 2019;19(1):229. http://dx.doi.org/10.1186/s12879-019-3814-9.

12. Duan SX, Li GX, Li XN, Chen C, Yan TF, Qiu FZ, et al. A probe directed recombinase amplification assay for detection of MTHFR A1298C polymorphism associated with congenital heart disease. Biotechniques 2018;64(5):211-7. http://dx.doi.org/10.2144/btn2018-2010.

13. Duan QX, Li XN, He XZ, Shen XX, Cao Y, Zhang RQ, et al. A duplex probe-directed recombinase amplification assay for detection of single nucleotide polymorphisms on $8 \mathrm{q} 24$ associated with prostate cancer. Braz J Med Biol Res 2021;54(2):e9549. http://dx.doi.org/10.1590/ 1414-431X20209549.

14. Hashemi SA, Khoshi A, Ghasemzadeh-Moghaddam H, Ghafouri M, Taghavi M, Namdar-Ahmadabad H, et al. Development of a PCRRFLP method for detection of D614G mutation in SARS-CoV-2. Infect Genet Evol 2020;86:104625. http://dx.doi.org/10.1016/j. meegid.2020.104625.

15. Du LY, He YX, Zhou YS, Liu SW, Zheng BJ, Jiang SB. The spike protein of SARS-CoV-a target for vaccine and therapeutic development. Nat Rev Microbiol 2009;7(3):226 - 36. http://dx.doi.org/10.1038/ nrmicro2090.

16. Hoffmann M, Kleine-Weber H, Schroeder S, Krüger N, Herrler T, Erichsen S, et al. SARS-CoV-2 cell entry depends on ACE2 and TMPRSS2 and is blocked by a clinically proven protease inhibitor. Cell 2020;181(2):271 - 80. http://dx.doi.org/10.1016/j.cell.2020.02.052.

17. Phan T. Genetic diversity and evolution of SARS-CoV-2. Infect Genet Evol 2020;81:104260. http://dx.doi.org/10.1016/j.meegid.2020. 104260.

18. Becerra-Flores M, Cardozo T. SARS-CoV-2 viral spike G614 mutation exhibits higher case fatality rate. Int J Clin Pract 2020;74(8):e13525. http://dx.doi.org/10.1111/IJCP.13525.

19. Niranji SS, Al-Jaf SMA. Comments on 'Development of a PCR-RFLP method for detection of D614G mutation in SARS-CoV-2'. Infect Genet Evol 2021;87:104661. http://dx.doi.org/10.1016/j.meegid. 2020.104661 